\title{
Central obesity and erectile dysfunction in men
}

\begin{abstract}
Development of intra-abdominal fat is associated with poor dietary habits and a sedentary lifestyle. The aim of this review was to analyse the relationship between central obesity and erectile dysfunciton (ED). The presence of a metabolic syndrome, associated with ED, is not characterized by a BMI value alone, but also takes into consideration an individual's waist circumference, body fat percentage, circulating levels of triacylglycerols, levels of low density lipoprotein (LDL) and high-density lipoprotein (HDL)-cholesterol, glycemic control and blood pressure. Of these factors, waist circumference (WC) was shown to be important in the diagnosis and treatment of both abdominal obesity and ED. WC is a strong indicator of an accumulation of visceral fat and a high WC in men is a risk factor for erectile dysfunction (ED), suggesting that $\mathrm{ED}$ is a complication of obesity, although the exact mechanisms of how obesity impacts ED on a molecular level are not well understood.
\end{abstract}

Keywords: visceral obesity, erectile dysfunction, sexual dysfunction
Volume 3 Issue 6 - 2019

\author{
Abdalla Ali Deb,' Chidiebere Emmanuel \\ Okechukwu, ${ }^{2}$ Shady Emara, ${ }^{3}$ Leony Gillott, ${ }^{4}$ \\ Sami A Abbas ${ }^{5}$ \\ 'Locum Consultant Urologist in NHS, UK \\ 2Physical activity and health promotion, Department of \\ Biomedicine and prevention, Faculty of Medicine and Surgery, \\ University of Rome Tor vergata, Italy \\ ${ }^{3}$ Urology Fellow, Western General Hospital, UK \\ ${ }^{4}$ Urology Physician Associate, Manchester Foundation NHS trust \\ ${ }^{5}$ Consultant Urologist; National Institute of Urology and \\ Nephrology; Cairo, Egypt
}

\begin{abstract}
Correspondence: Abdalla Ali Deb, Locum Consultant Urologist in NHS - UK, Tel +447456070200,

Email drabdodeeb@hotmail.com
\end{abstract}

Received: November 28, 2019 | Published: December 12, 2019
Abbreviations: ED, erectile dysfunction; LDL, low density lipoprotein; HDL, high-density lipoprotein; WC, waist circumference; WHO, the world health organization; BMI, body mass index; DM, diabetes mellitus; CRP, c-reactive protein; MS, metabolic syndrome; MET, metabolic equivalent

\section{Introduction}

The World Health Organization (WHO) ${ }^{1}$ defines obesity as an excessive accumulation of fat that presents a risk to health. WHO crudely characterises body weight by first determining the body mass index (BMI) of an individual. BMI is calculated as body weight in kilograms divided by height in meters squared. Based on the value calculated, individuals with a BMI of 25 to $29.9 \mathrm{~kg} / \mathrm{m}^{2}$ are classified as overweight while obesity is identified as a BMI value of $\geq 30 \mathrm{~kg} /$ $\mathrm{m}^{2}$. Obesity is further subdivided into three categories: class I (BMI ranging from 30 to $34.9 \mathrm{~kg} / \mathrm{m}^{2}$ ), class II (BMI ranging from 35.0 to $\left.39.9 \mathrm{~kg} / \mathrm{m}^{2}\right)$, and class III (BMI $\left.\geq 40 \mathrm{~kg} / \mathrm{m}^{2}\right) .^{2}$ At least $30 \%$ of the male population in North America, Europe, Australia and Asia are obese. ${ }^{3,4}$ Obesity, in particular the accumulation of abdominal fat is a major risk factor in the development of a number of chronic diseases and is often the result of poor diet, sleep disorders and a sedentary lifestyle. Intra-abdominal visceral fat contains hypertrophied adipocytes, and are resistant to insulin. ${ }^{5}$ High level of free fatty acid and glycerol in the portal vein leads to free fatty acidemia and hyperglycerolemia which results to an increased production of triacylglycerol-bound lipoproteins and glucose in the liver. ${ }^{6}$ Obesity is not characterised by BMI value alone, but an individual's waist circumference, waisthip ratio, circulating levels of triacylglycerols, levels of low density lipoprotein (LDL) and high-density lipoprotein (HDL)-cholesterol, fasting glucose and blood pressure are considered. ${ }^{7}$ Visceral obesity, irrespective of other body fat deposits, is a major risk factor for systemic inflammation and cardiovascular disease. ${ }^{8}$
Waist circumference is one of the most important factors in the diagnosis of abdominal obesity, ${ }^{9}$ and is a strong indicator of an accumulation of intra-abdominal fat. ${ }^{10}$ According to WHO, a waist circumference greater than $94 \mathrm{~cm}$, classifies a man as obese. ${ }^{19}$ However waist circumference is not used alone. Body fat percentage and BMI are also taken into consideration (Table 1) and (Table 2). ${ }^{11}$ A greater waist circumference in men has been shown to be a risk factor for erectile dysfunction (ED). ${ }^{12} \mathrm{ED}$ is the inability to attain and/ or maintain a penile erection sufficient enough to allow satisfactory sexual intercourse. It is a common sexual dysfunction, the incidence of which varies with ethnicity and increases with age. ${ }^{13}$ The presence of atherosclerotic vessels in the penis is thought to be one of the major causes of organic ED. ${ }^{14}$ There is a strong link between organic ED and the risk factors associated with atherosclerosis, such as hypertension, diabetes mellitus (DM), dyslipidaemia, a sedentary lifestyle, obesity, and smoking. ${ }^{15,16}$ The severity of ED is known to correlate with the number and severity of the aforementioned risk factors, i.e. the more risk factors a person has the higher the incidence of ED.${ }^{17}$ Obesity has a significant impact on whether or not an individual develops ED but the exact correlation is not fully understood. This paper highlights the need for further research incorporating frontline data from clinicians and close collaboration with the scientific community, to better understand the role central obesity has in the development of ED. The aim of this review was to analyse the relationship between visceral obesity and ED.

\section{Methods}

\section{Search strategy}

Studies that reported on obesity and ED in men from 1994 to 2018, published in English were included in this review. The following electronic databases were used: PubMed, and Science Direct. These databases were searched by combining one or more of the following 
keywords: Visceral obesity, Body Mass Index, erectile dysfunction, metabolic syndrome, waist circumference and sexual dysfunction. The MeSH system was used to search and extract relevant research studies from PubMed.

\section{Types of studies}

Original articles, meta-analyses, systematic reviews and WHO Technical Report.

\section{Inclusion and exclusion criteria}

Articles were selected based on specificity. Articles were required to discuss at least one of the following: central obesity and ED, obesity and ED, BMI and ED, waist circumference and ED. Articles that did not compare these factors were deemed irrelevant and excluded in the final review. In total 55 studies were included in this review. Figure 1 below represents a schematic view of data extraction and the management of that data.

Table I Classification of Obesity based on Body Mass Index (BMI)

\begin{tabular}{lll}
\hline Anthropometric condition & BMI $\left(\mathbf{k g} / \mathbf{m}^{2}\right)$ & Comment \\
\hline Under weight & $<18.5$ & - \\
Normal & $18.5-24.9$ & - \\
Over weight & $25.0-29.9$ & Increased \\
Obesity (class) & & \\
I & $30.0-34.9$ & High \\
$\quad$ II & $35.0-39.9$ & Very High \\
III (extreme obesity) & $\geq 40$ & Extremely High \\
\hline
\end{tabular}

Table 2 Classification of Waist Circumference (WC) in men and women

\begin{tabular}{llll}
\hline Waist circumference (WC) & Men & Women & Comment \\
\hline Normal & $\leq 102$ & $\leq 88 \mathrm{~cm}$ & - \\
High & $\mathrm{cm}$ & & $\begin{array}{l}\text { High risk of abdominal obesity coupled with other } \\
\text { metabolic syndrome and cardiovascular disease }\end{array}$ \\
\hline
\end{tabular}

Table 3 Prospective and cross-sectional observational studies on the association between obesity and ED in men

\begin{tabular}{|c|c|c|}
\hline Studies & Classification of obesity $\left(\mathrm{kg} / \mathrm{m}^{2}\right)$ & Results \\
\hline Feldman et al. ${ }^{15 a}$ & $\mathrm{BMI}>28$ vs others & Positive association ${ }^{\mathrm{b}}$ \\
\hline Derby et al. ${ }^{29 a}$ & $\mathrm{BMI} \geqslant 30$ vs others & Positive association ${ }^{\mathrm{b}}$ \\
\hline \multirow[t]{3}{*}{ Shiri et al. ${ }^{40}$} & Obesity: $\mathrm{BMI} \geqslant 30$ vs & Positive association \\
\hline & Overweight: BMI: $25-29.9$ or & \\
\hline & Normal: BMI: I8.5-24.5 & \\
\hline Fung et al. ${ }^{25}$ & $\mathrm{BMI}>28$ vs others & Positive association ${ }^{\mathrm{b}}$ \\
\hline \multicolumn{3}{|l|}{ Cross-sectional } \\
\hline Feldman et al. ${ }^{15 a}$ & $>120 \%$ ideal body weight vs others & No association \\
\hline Chung et al..$^{41}$ & $<120 \%$ ideal body weight vs $\geqslant 20 \%$ & Positive association \\
\hline Blanker et al. ${ }^{42}$ & $\mathrm{BMI}<25$ vs $\mathrm{BMI} \geqslant 25$ & Positive association ${ }^{b}$ \\
\hline Bacon et al..$^{30}$ & $\mathrm{BMI}<23.2$ vs $\mathrm{BMI}>28.7$ & Positive association \\
\hline \multirow[t]{3}{*}{ Adolfsson et al. ${ }^{43}$} & Obesity: $\mathrm{BMI} \geqslant 30$ vs & No ED results. \\
\hline & Overweight: BMI: 25-29.9 & Found significant decreased sexual desire \\
\hline & Normal: BMI: I8.5-24.5 & \\
\hline \multirow[t]{3}{*}{ Gunduz et al. ${ }^{44 c}$} & Obesity: BMI $\geqslant 30$ & Positive association \\
\hline & Overweight: BMI: 25-29.9 & \\
\hline & Normal: BMI: I8.5-24.5 & \\
\hline Giugliano et al. ${ }^{45}$ & BMI $>28.7$ vs others & Positive association \\
\hline
\end{tabular}

Abbreviations: BMI, body mass index; ED, erectile dysfunction a: Data from the MMAS (Massachusetts Male Aging study) b: Statistically significant c: Coronary artery disease patients 


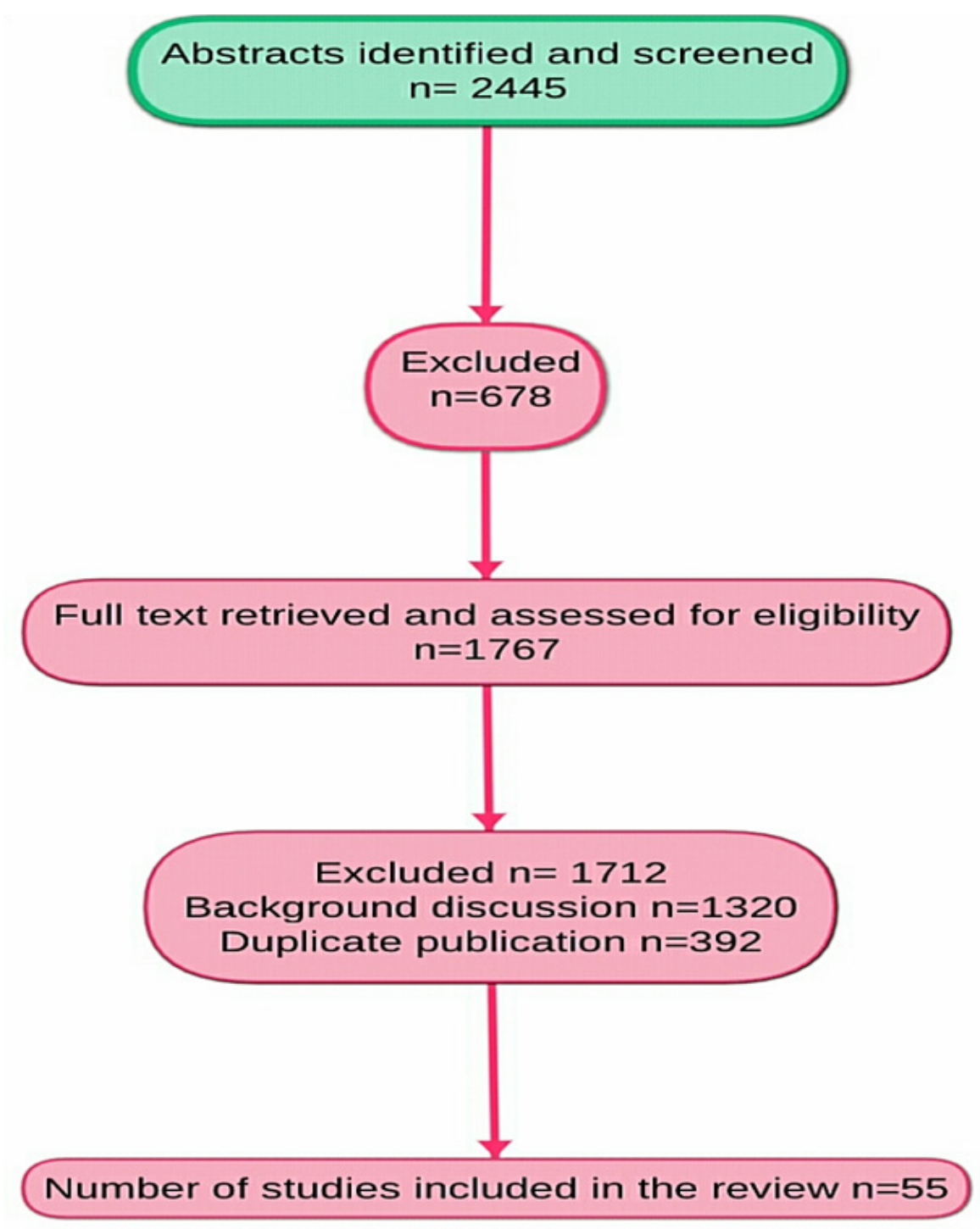

Figure I Preferred Reporting Items for Systematic Reviews and Meta-analyses (PRISMA) flow diagram.

\section{Pathogenesis of erectile dysfunction in obesity}

According to the literature reviewed, the pathogenesis of ED in obese males was multifactorial and may not only be attributed to endothelial dysfunction due to destructive inflammatory processes, but also to hypogonadism, as testosterone levels were often low in obese males with ED. ${ }^{18}$ Obesity is considered as a pro-inflammatory state, which leads to both endocrine and endothelial dysfunction, resulting in ED. Peri-visceral adipocytes were shown to significantly increase the production of pro-inflammatory cytokines, than other types of adipocyte found within the body ${ }^{27,28}$ and weight loss was shown to reduce the serum concentrations of the inflammatory markers C-reactive protein (CRP), and interleukin (IL-8 \& IL-6), indicating that like all obesity related disorders, weight loss is often beneficial and should be considered as first line treatment. ${ }^{20,21}$

\section{The relationship between erectile dysfunction and central obesity}

The prevalence of ED was higher in males with a BMI of $25-30 \mathrm{~kg} /$ $\mathrm{m}^{2}$, and significantly higher in those with a BMI $>30 \mathrm{~kg} / \mathrm{m}^{2}$ than those with a BMI which is considered normal $\left(<25 \mathrm{~kg} / \mathrm{m}^{2}\right)$. The waist-to-hip ratio and abdominal circumference was independently associated with a higher risk of ED. ${ }^{22,23,24,25}$ Riedner et al. ${ }^{26}$ showed that central obesity was a predictor of ED among males aged 61 to 81 years, along with other associated factors such as, excessive alcoholic intake, smoking, sedentary lifestyle, hyperglycaemia, increased BMI, dyslipidaemia and hypogonadism. ${ }^{26}$ Similar results were obtained in European studies. ${ }^{31,32,33}$ Central obesity is a predictor of ED even in the absence of other risk factors such as diabetes mellitus and hypertension. ${ }^{34}$ Moreover, a significant association between central obesity and ED 
was identified among young males without a history of systemic disease. ${ }^{35}$ Several studies showed a strong association between ED and metabolic syndrome (MS). ${ }^{36,37}$ However, Kupelian et al. ${ }^{36}$ concluded that ED was a risk factor for the development of metabolic syndrome.${ }^{37}$ Bacon et al ${ }^{37}$ investigated Sexual health and function in men older than 50 years of age. The study showed that physical activity was associated with a lower risk of erectile dysfunction at $>32.6$ metabolic equivalent (MET) hours of exercise week ${ }^{-1}$ against 0 to 2.7 MET hours of exercise week ${ }^{-1}$, and obesity (body mass index $>28.7 \mathrm{~kg} / \mathrm{m}^{2}$ vs. $<23.2 \mathrm{~kg} / \mathrm{m}^{2}$ ) was associated with higher risk. ${ }^{38}$

Cigarette Smoking, alcohol consumption, and time spent while watching the television were associated with the risk of ED, men who had no chronic medical conditions and frequently engaged in healthy behaviors had the lowest prevalence, however lifestyle modifiable factors most strongly associated with ED were physical inactivity and obesity. ${ }^{38}$ In a survey of health professionals, obesity was found to be associated with a 1.3-fold increased risk of ED. ${ }^{39}$ In a prospective study of risk factors for ED, obesity and smoking were found to be positively associated with ED, but physical activity was inversely associated with the risk of developing ED during a 14-year follow-up period. $^{30}$

\section{Summary}

According to the Massachusetts Male Aging study, there was no association between BMI and ED. ${ }^{15}$ In contrast, a cross-sectional study including 2,126 men showed an identifiable but weak relationship between obesity and $\mathrm{ED},{ }^{46}$ the study revealed that central obesity was associated with the development of erectile dysfunction in patients older than 60 years. ${ }^{46}$ The presence of erectile dysfunction can be determined by sagittal abdominal diameter; abdominal diameterheight index, WC and waist-hip index. ${ }^{47}$ Exercise and obesity interventions were effective in the prevention of ED by increasing the level of circulating adiponectin. ${ }^{48,49}$ Sowers, ${ }^{50}$ suggested that physical activity is effective in reducing circulating C-reactive protein (CRP) and tumor necrosis factor-alpha (TNF $)$,thereby decreasing inflammation, endothelial cell apoptosis and adhesion molecules expression, possibly leading to a reduced incidence of ED. Lifestyle interventions led to improvements in the five-question International Index of Erectile Function (IIEF-5) scores in men with ED. ${ }^{51}$ This modification can be achieved by participating in regular exercise, diabetes control, blood pressure control, and a weight loss program ${ }^{52}$ The use of statins for lowering lipid levels also appeared to improve $\mathrm{ED},{ }^{53}$ implicating the role of cholesterol and the destructive process of atherosclerosis in ED. In support of this a prospective study by Esposito et al. ${ }^{54}$ including 55 men with ED treated by caloric reduction and consistent exercise, showed that there was 31\% regain of normal erectile function in the treatment group compared to $2 \%$ in the control. ${ }^{54}$ A study conducted by Kalka et al. ${ }^{55}$ demonstrated that patients with ischemic heart disease had limited knowledge on the relationship between cardiovascular risk factors and ED, suggesting the need for an education aspect of ED treatment.

\section{Conclusion}

Based on the evaluated studies there is an association between visceral obesity, and erectile dysfunction in men. However, the pathophysiological mechanisms of how this occurs, largely how penile microcirculation is interrupted by an accumulation of visceral fat is still unknown. In the subgroup of obese men, the prevalence of ED is much higher than in those men that are not classified as obese, but prevalence also increases with age and differs amongst ethnicity. What is apparent is that obesity isn't alone as a possible causative agent of organic ED. Equally, leading a generally unhealthy lifestyle, being a smoker and consuming increased amounts of alcohol, all play a role, that could be exacerbated further by obesity. Further research is required in order to fully understand the role obesity has in ED.

\section{Acknowledgments}

None.

\section{Conflicts of interest}

The author declares there is no conflict of interest.

\section{References}

1. World Health Organization (WHO Technical Report Series, No. 894). Obesity: preventing and managing the global epidemic: report of a WHO consultation. Geneva, Switzerland. 2000.

2. P Poirier, TD Giles, GA Bray, et al. Obesity and cardiovascular disease: pathophysiology, evaluation, and effect of weight loss. Arterioscler Thromb Vasc Biol. 2006;26(5):968-976.

3. Collaborators GBDO, Afshin A, Forouzanfar MH, et al. Health effects of overweight and obesity in 195 countries over 25 years. $N$ Engl J Med. 2017;377(1):13-27.

4. $\mathrm{M} \mathrm{Ng}$, Fleming T, Robinson M, et al. Global, regional, and national prevalence of overweight and obesity in children and adults during 1980-2013: a systematic analysis for the global burden of disease study 2013. Lancet. 2014;384(9945):766-781.

5. Mittelman SD, Van CGW, Kirkman EL, Bergman R. Extreme insulin resistance of the central adipose depot in vivo. Diabetes. 2002;51(3):755761.

6. Londos C, Brasaemle DL, Schultz CJl. Review On the control of lipolysis in adipocytes. Ann N Y Acad Sci. 1999;892(18):155-168.

7. Galassi A, Reynolds K, He J. Metabolic syndrome and risk of cardiovascular disease: a meta-analysis. Am J Med. 2006;119(10):812819.

8. Pedersen BK, Saltin B. Exercise as medicine - evidence for prescribing exercise as therapy in 26 different chronic diseases. Scand J Med Sci Sports. 2015;25(Supple 3):1-72.

9. Executive Summary of The Third Report of The National Cholesterol Education Program (NCEP) Expert Panel on Detection, Evaluation, And Treatment of High Blood Cholesterol In Adults (Adult Treatment Panel III). J Am Med Assoc. 2001;285(19):2486-2497.

10. Janssen I, Katzmarzyk PT, Ross R. Waist circumference and not body mass index explains obesity-related health risk. Am J Clin Nutr. 2004;79(3):379-384

11. Clinical Guidelines on the Identification, Evaluation, and Treatment of Overweight and Obesity in Adults-The Evidence Report. National Institutes of Health. Obes Res. 1998;2 (Supple 2):51S-209S.

12. Gorgel SN, Gorgel A, Sefik E. Sexual Function in Male Patients with Metabolic Syndrome and Effective Parameters on Erectile Dysfunction. International Braz J Urol. 2014;40(1):56-61.

13. Nicolosi A, Moreira Jr ED, Shirai M, et al. Epidemiology of erectile dysfunction in four countries: cross-national study of the prevalence and correlates of erectile dysfunction. Urology. 2003;61(1):201-206.

14. Melman A, Gingell JC. The epidemiology and pathophysiology of erectile dysfunction. $J$ urol. 1999;161(1):5-11. 
15. Feldman HA, Goldstein I, Hatzichristou DG, et al. Impotence and its medical and psychosocial correlates: results of the Massachusetts Male Aging Study. J urol. 1994;151(1):54-61.

16. Parazzini F, Fabris FM, Bortolotti A, et al. Frequency and determinants of erectile dysfunction in Italy. Eur Urol. 2000;37(1):43-49.

17. Makhsida N, Shah J, Yan G, et al. Hypogonadism and metabolic syndrome: implications for testosterone therapy. J urol. 2005;174(3):827-834.

18. Diaz-Arjonilla M, Schwarcz M, Swerdloff RS, et al. Obesity, low testosterone levels and erectile dysfunction. Int $J$ Impot Res. 2009;21(2):89-98.

19. Seftel A. Male hypogonadism. Part II: etiology, pathophysiology, and diagnosis. Int J Impot Res. 2006;18(3):223-228.

20. Meneilly GS, Battistini B, Floras JS. Contrasting effects of L-arginine on insulin-mediated blood flow and glucose disposal in the elderly. Metabolism. 2001;50(2):194-199.

21. Isidori AM, Caprio M, Strollo F, et al. Leptin and androgens in male obesity: evidence for leptin contribution to reduced androgen levels. $J$ Clin Endocr Metab. 1999;84(10):3673-3680.

22. Corona G, Mannucci E, Petrone L, et al. A Comparison of NCEP-ATPII and IDF Metabolic Syndrome Definitions with Relation to Metabolic Syndrome-Associated Sexual Dysfunction. J Sex Med. 2007;4(3):789796.

23. Traish AM, Guay A, Feeley R, et al. The dark side of testosterone deficiency: I. Metabolic syndrome and erectile dysfunction. J Androl. 2009;30(1):10-22.

24. Demir O, Akgul K, Akar Z, et al. Association between severity of lower urinary tract symptoms, erectile dysfunction and metabolic syndrome. The Aging Male. 2009;12(1):29-34.

25. Fung MM, Bettencourt R, Barrett-Connor E. Heart disease risk factors predict erectile dysfunction 25 years later: the Rancho Bernardo Study. $J$ Am Coll Cardiol. 2004;43(8):1405-1411.

26. Riedner CE, Rhoden EL, Ribeiro EP, et al. Central obesity is an independent predictor of erectile dysfunction in older men. $J$ Urol. 2006;176(4):1519-1523.

27. Fain JN, Madan AK, Hiler ML, et al. Comparison of the release of adipokines by adipose tissue, adipose tissue matrix, and adipocytes from visceral and subcutaneous abdominal adipose tissues of obese humans. Endocrinol. 2004;145(5):2273-2282.

28. Fillo J, Levcikova M, Ondrusova M, et al. Importance of Different Grades of Abdominal Obesity on Testosterone Level, Erectile Dysfunction, and Clinical Coincidence. Am J Mens Health. 2017;11(2):240-245.

29. Derby CA, Mohr BA, Goldstein I, et al. Modifiable risk factors and erectile dysfunction: can lifestyle changes modify risk? Urology. 2000;56(2):302-306.

30. Bacon CG, Mittleman MA, Kawachi I, et al. A prospective study of risk factors for erectile dysfunction. J urol. 2006;176(1):217-221.

31. Andersen I, Heitman BL, Wagner G. Obesity and sexual dysfunction in younger Danish men. J Sex Med. 2008;5(9):2053-2060.

32. Corona G, Lee DM, Forti G, et al. Age $\square$ related changes in general and sexual health in middle $\square$ aged and older men: Results from the European Male Ageing Study (EMAS). J Sex Med. 2010;7(4 pt1):1362-1380.

33. Larsen S, Wagner G, Heitmann BL. Sexual function and obesity. Int J Obesity. 2007;31(8):1189-1198.

34. Tsao CW, Hsu CY, Chou YC, et al. Is obesity correlated with sexual function in young men? J Androl. 2009;30(3):275-279.

35. Demir T. Prevalence of erectile dysfunction in patients with metabolic syndrome. Int J Urol. 2006;13(4):385-388.

36. Bansal TC, Guay AT, Jacobson J, et al. Incidence of Metabolic Syndrome and Insulin Resistance in a Population with Organic Erectile Dysfunction. J Sex Med. 2005;2(1):96-103.

37. Kupelian V, Shabsigh R, Araujo AB, et al. Erectile dysfunction as a predictor of the metabolic syndrome in aging men: results from the Massachusetts Male Aging Study. J urol. 2006;176(1):222-226.

38. Bacon CG, Mittleman MA, Kawachi I, et al. Sexual function in men older than 50 years of age: results from the health professionals followup study. Ann Intern Med. 2003;139(3):161-168.

39. Feldman HA, Johannes CB, Derby CA, et al. Erectile dysfunction and coronary risk factors: prospective results from the Massachusetts male aging study. Prev med. 2000;30(4):328-338.

40. Shiri R, Koskimäki J, Hakama M, et al. Effect of life-style factors on incidence of erectile dysfunction. Int J Impot Res. 2004;16(5):389-394.

41. Chung WS, Sohn JH, Park YY. Is obesity an underlying factor in erectile dysfunction? Eur urol. 1999;36(1):68-70.

42. Blanker MH, Bohnen AM, Groeneveld FP, et al. Correlates for erectile and ejaculatory dysfunction in older Dutch men: A community $\square$ based study. J Am Geriatr Soc. 2001;49(4):436-442.

43. Adolfsson B, Elofsson S, Rössner S, et al. Are sexual dissatisfaction and sexual abuse associated with obesity? A population $\square$ based study. Obes Res. 2004;12(10):1702-1709.

44. Gunduz M, Gumus B, Sekuri C. Relationship between metabolic syndrome and erectile dysfunction. Asian J Androl. 2004;6(4):355-358.

45. Giugliano F, Esposito K, Di Palo C, et al. Erectile dysfunction associates with endothelial dysfunction and raised proinflammatory cytokine levels in obese men. J Endocrinol Invest. 2004;27(7):665-669.

46. Selvin E, Burnett AL, Platz EA. Prevalence and risk factors for erectile dysfunction in the US. Am J Med. 2007;120(2):151-157.

47. Riedner CE, Rhoden EL, Ribeiro EP, et al. Central Obesity is an Independent Predictor of Erectile Dysfunction in Older Men. J Urol. 2006;176(4):1519-1523.

48. Kolotkin R, Binks M, Crosby R, et al. Improvements in sexual quality of life after moderate weight loss. Int J Impot Res. 2008;20(5):487-492.

49. Dallal RM, Chernoff A, O'Leary MP, et al. Sexual dysfunction is common in the morbidly obese male and improves after gastric bypass surgery. J Am Coll Surgeons. 2008;207(6):859-864.

50. Sowers JR. Endocrine functions of adipose tissue: focus on adiponectin. Clinical cornerstone. 2008;9(1):32-40.

51. Gupta BP, Murad MH, Clifton MM, et al. The effect of lifestyle modification and cardiovascular risk factor reduction on erectile dysfunction: a systematic review and meta-analysis. Arch Intern Med. 2011;171(20):1797-1803.

52. Corona G, Rastrelli G, Monami M, et al. Body weight loss reverts obesity-associated hypogonadotropic hypogonadism: a systematic review and meta-analysis. Eur J Endocrinol. 2013;168(6):829-843.

53. Kostis JB, Dobrzynski JM. The effect of statins on erectile dysfunction: A meta $\square$ analysis of randomized trials. J Sex Med. 2014;11(7):1626-1635.

54. Esposito K, Giugliano F, Di Palo C, et al. Effect of lifestyle changes on erectile dysfunction in obese men: a randomized controlled trial. JAMA. 2004;291(24):2978-2984.

55. Kałka D, Domagała Z, Rakowska A, et al. Modifiable risk factors for erectile dysfunction: an assessment of the awareness of such factors in patients suffering from ischaemic heart disease. Int $J$ Impot Res. 2016;28(1):14-19. 